\title{
A SEPARAÇÃO ENTRE PODERES, AS DECISÕES JUDICIAIS E A LEI DO CÓDIGO FLORESTAL: INTERCESSÕES DE UM DEBATE NECESSÁRIO EM UMA SOCIEDADE DEMOCRÁTICA
}

\author{
Rafaela Aiex Parra ${ }^{1}$ \\ Elve Miguel Cenci ${ }^{2}$
}

\begin{abstract}
Resumo: As decisões judiciais, tal qual essência de jurisdição estatal, são consideradas instrumentos de controle da democracia e ordem social. A separação dos poderes é o cerne para entender o porque as decisões devem ser respeitadas. Via reflexa, o formalismo adstrito às decisões judiciais deve ser contemplado para que surtam todos os efeitos ao senso coletivo. Este trabalho se ocupa de analisar a premissa de que toda decisão, restrita ou abrangente, seja feita parametrizada em bases legais, enfatizando a necessidade de aplicação, pelo judiciário, do texto do Código Florestal em suas decisões, sob pena de incorrer em disseminação de insegurança jurídica.
\end{abstract}

Palavras-chave: Decisão Judicial; Separação de Poderes; Segurança Jurídica; Código Florestal; Meio Ambiente.

\section{THE SEPARATION BETWEEN POWERS, JUDICIAL DECISIONS AND THE LAW OF THE FOREST CODE: INTERCESSIONS OF A NEEDED DEBATE IN A DEMOCRATIC SOCIETY}

\begin{abstract}
Judicial decisions, as an essence of state jurisdiction, are considered instruments of control of democracy and social order. The separation of powers is at the heart to understand why decisions must be respected. Also, the formalism attached to judicial decisions, must be contemplated so that all effects have their effect on the collective sense. This paper analyzes the premise that any decision, whether restricted or comprehensive, should be parameterized on a legal basis, emphasizing the need to apply, by the judiciary, the text of the Forest Code in its decisions, under penalty of spreading insecurity Legal basis.
\end{abstract}

Keywords: Judicial Decision; Separation of Powers; Legal Security; Forest Code; Environment.

\footnotetext{
1 E-mail: rp@advocaciarp.adv.br; Telefone: (43) 98801-8296; Endereço: Rua João Wyclif, 111, 4º andar, sala 410, CEP 86050-450, Londrina - PR; Profissão: Advogada; Mestranda em Direito Negocial pela Universidade Estadual de Londrina UEL (PR); Aluna Regular do Projeto de Pesquisa: A relação entre economia, direito e democracia na agenda do século XXI da Universidade Estadual de Londrina - UEL (PR); Orientador: Prof. Dr. Elve Miguel Cenci.

2 E-mail: elve@uel.br; Telefone: (43) 99937-3703; Endereço: Rodovia Celso Garcia Cid, PR 445, KM 380, s/n, CEP: 86051 980, Campus Universitário, CESA - Centro de Estudos Sociais Aplicados; Profissão: Advogado; Doutor em Filosofia pela Universidade Federal do Rio de Janeiro - UFRJ/RJ; Docente associado à Universidade Estadual de Londrina - UEL (PR); Coordenador do Mestrado em Direito Negocial da Universidade Estadual de Londrina - UEL (PR).
} 


\section{CONSIDERAÇÕES INICIAIS}

O Direito e sua estrutura jurídica estão visceralmente jungidos à sociedade e sua estrutura social. Com a evolução da sociedade, principalmente nos períodos de transição entre o séculos XX e XXI, houve um aumento dos conflitos que decorrem, majoritariamente, da economia.

O Estado, então, assumiu papel preponderante para a manutenção do equilíbrio nesta seara conflitiva entre interesses individuais e coletivos, como é o caso da defesa do meio ambiente e a manutenção da sustentabilidade (social, produtiva e ambiental), como princípios fundamentais da democracia representativa, participativa e pluralista e a garantia dos direitos fundamentais do homem, exemplificados pelo art. 225 da CF em esfera ambiental .

Neste sentido, é possível afirmar que o Poder Judiciário, em sendo um dos poderes balizadores do Estado, é regulado pelo hermenêutico dever de prestar-se ao exercício de suas funções, estritamente como previstas na Constituição Federal, com o fito de ser instituição dotada de confiança aos olhos da sociedade.

Este exercício do judiciário é fundamental para o equilíbrio instrumental, político e simbólico do Direito, na medida em que decide conflitos, evita ou cria soluções, floresce mecanismos de controle social e, não menos importante, calibra expectativas jurídicas e reforça padrões de legitimidade, em um Estado democrático, como é o Brasil $\left(\operatorname{art.} 1^{\circ}\right.$ da Constituição da República).

O presente artigo encontra-se exatamente sob este enfoque. Assim, será abordada a definição e as razões da separação dos poderes para a solidez do Estado democrático de Direito. Logo após, far-se-á menção à legitimidade da lei 12.651/2012 (Código Florestal). Após, será abordado o papel do Estado Social e sua atuação positiva na instauração da segurança jurídica, trazendo-se, logo em seguida, noções importantes dos reflexos de uma sociedade que busque o entendimento para a economia e a própria democracia do país.

Portanto, o presente texto busca investigar qual a importância do Poder Judiciário para manutenção da democracia, da ordem social e da estabilidade econômica e jurídica a partir de problematização ambiental.

Ainda que a democracia e o papel do Estado, após a crise de 1929, estejam em constante evolução, notadamente em razão dos processos de globalizacão e, mais adiante, de 


\section{A SEPARAÇÃO ENTRE PODERES, AS DECISÕES JUDICIAIS E A LEI DO CÓDIGO FLORESTAL: INTERCESSÕES DE UM DEBATE NECESSÁRIO EM UMA SOCIEDADE DEMOCRÁTICA}

transnacionalização, as discussões sobre bem estar social e direitos fundamentais ambientais, aindam permanecem atuais e no topo da agenda planetária.

Justifica-se o presente trabalho, assim, exatamente porque o Estado (e a sociedade) necessitam concretizar a matéria jurídico ambiental em ponto convergente no que tange à sustentabilidade e não como causadora de desequilíbrio e segregação entre os povos, diante da importância da matéria.

O trabalho valeu-se, para fins metodológicos, da reconstrução da bibliografia pertinente ao tema, buscando guardar a necessária coesão e coerência com o objetivo final do texto, a saber, discutir um problema atual e pertinente do nosso tempo tendo como referência bibliografia atual e relevante.

O estudo possui relevância e atualidade. Merece que se debrucem os cientistas e estudiosos do Direito e de áreas afins, porquanto ainda prescinde de farta doutrina específica do tema, que, ainda, é novo.

\section{A TRIPARTIÇÃO DO PODER E AS LEIS: GARANTIA DA ORDEM ESTATAL}

A separação ou tripartição dos poderes é uma teoria desenvolvida por vários autores, sobretudo ao longo da modernidade, a exemplo de Rousseau, Kant, Locke e Montesquieu. O modelo que prevaleceu na história e que está consagrado nas constituições é o de Montesquieu, presente em sua obra "O Espírito das Leis" (1748).

O sistema politico brasileiro, em seu art. $2^{\circ}$ da promulgada Constituição da República de 1988, prevê, como direito fundamental, a divisão dos poderes, ipsis litteris: "Art. $2^{\circ}$ São Poderes da União, independentes e harmônicos entre si, o Legislativo, o Executivo e o Judiciário" (CF/88, art. $\left.2^{\circ}\right)$. O objetivo da divisão do poder estatal é assim explicado pelo doutrinador José Afonso da Silva (2004, p.109):

A divisão de poderes fundamenta-se, pois, em dois elementos: (a) especialização funcional, significando que cada órgão é especializado no exercício de uma função; assim, às assembleias (Congresso, Câmaras, Parlamento) se atribui a função Legislativa; ao Executivo, a função executiva; ao Judiciário, a função jurisdicional; (b) independência orgânica, significando que, além da especialização funcional, é necessário que cada órgão seja efetivamente independente dos outros, o que postula ausência de meios de subordinação.

O autor vai além e discorre sobre a história da tripartição dos poderes: 
O princípio da separação de poderes já se encontra sugerido em Aristóteles, John Locke e Rousseau, que também conceberam uma doutrina de separação de poderes, que, afinal, em termos diversos, veio a ser definidas e divulgada por Montesquieu. (...). Tornou-se, com a Revolucão Francesa, um dogma constitucional, a ponto de o art. 16 da Declaração dos Direitos do Homem e do Cidadão de 1789 declarar que não teria constituição a sociedade que não assegurasse a separação de poderes, tal a compreensão de que ela constituiu técnica de extrema relevância para a garantia dos Direitos do Homem, como ainda o é

Inserido nesse sistema estatal, está a lei e o seu processo de criação. No Brasil, a elaboração de leis é fruto da função parlamentar de legislar e fiscalizar, que culmina no processo legislativo, sendo orientado por regras internas inerentes às casas legislativas.

Ainda que exista a tripartição do poder estatal, todos os poderes podem e devem exercer o poder de fiscalização visando a boa e correta aplicação da lei. Todavia, esse poder fiscalizatório não se confunde com inovação desprovida de autorização legal, e, tampouco autoriza o pensante do Direito a usurpar atribuições que não sejam inerentes à função exercida.

Nas palavras de Celso Antonio Bandeira de Melo (2017, p. 49):

No Estado de Direito quer-se o governo das leis e não o governo dos homens, consoante a clássica assertiva proveniente do Direito inglês. Isto significa que é ao Poder Legislativo que assiste o encargo de traçar os objetivos públicos a serem perseguidos e de fixar os meios e os modos pelos quais hão de ser buscados, competindo à Administração, por seus agentes, o mister, o dever, de cumprir dócil e fielmente os desiderata legais, segundo os termos estabelecidos em lei. Assim, a atividade administrativa encontra na lei tanto seus fundamentos quando seus limites."

A obrigatoriedade da lei atinge a todos e, deve ser aplicada por todos, estritamente e interpretativamente ao que diz o texto legal, para organizar a sociedade, criar regras e salvaguardar condutas. Essas leis tem de ser claras e sua aplicação impositiva, sob pena de haver a caracterização de desvio de poder.

Sobre a finalidade dos atos administrativos, como é o caso da função jurisdicional, o autor nos ensina (2017, p. 13):

A ordenação normativa propõe uma série de finalidades a serem alcançadas, as quais se apresentam, para quaisquer agentes estatais, como obrigatórias. A busca destas finalidades tem o caráter de dever (antes do que "poder"), caracterizando uma função, em sentido jurídico. 


\section{A SEPARAÇÃO ENTRE PODERES, AS DECISÕES JUDICIAIS E A LEI DO CÓDIGO FLORESTAL: INTERCESSÕES DE UM DEBATE NECESSÁRIO EM UMA SOCIEDADE DEMOCRÁTICA}

Esta questão sobre a subvenção do homem às leis e a necessidade deste formalismo para figuração de liberdade sob a égide moderna, é assim definida por Benjamin Constant (1985, p.18):

\footnotetext{
A nação não pensava que uma parte ideal de uma soberania abstrata valesse os sacrifícios que lhe pediam. Em vão repetiam-lhe Rousseau: as leis da liberdade são mil vezes mais austeras do que é o duro jugo dos tiranos. Ela não aceitava essas leis austeras e, em seu descontentamento, pensava às vezes que o jugo dos tiranos seria preferível. A experiência a desenganou. Ela viu que a arbitrariedade dos homens era pior ainda que as piores leis.
}

Assim, é silógico concluir que, como o poder emana do povo e sua representação se dá sob a forma legislativa, é imperioso que o sujeito estatal aplicador das leis exerça a sua função em observância à finalidade configurada pela lei como útil ao todo social.

\section{O PODER JUDICIÁRIO E A APLICAÇÃo DO CÓDIGO FLORESTAL COMO INSTRUMENTO LEGAL: A QUESTÃO DA SEGURANÇA JURÍDICA}

$\mathrm{O}$ art. 225 da Constituição Federal, preve em seu caput o direito fundamental à proteção do meio ambiente. Acredita-se ser a função ambiental um dos mais importantes instrumentos atuais de proteção dos direitos e liberdade dos povos. Tanto o é, que o assunto foi deliberado em capítulo próprio, intitulado "DO MEIO AMBIENTE”. Vejamos: Art. 225. "Todos têm direito ao meio ambiente ecologicamente equilibrado, bem de uso comum do povo e essencial à sadia qualidade de vida, impondo-se ao Poder Público e à coletividade o dever de defendê-lo e preservá- lo para as presentes e futuras gerações”.

A promulgação da Constituição de 1988 foi resultado de uma evolucão dos conceitos absolutos que conferiam amplos poderes aos direitos individuais, passando a sopesá-los com as aspirações coletivas.

A Revolução Liberal já havia introduzido o debate sobre o uso da propriedade, atribuindo-lhe um caráter social. Tal suposição foi albergada pelo Direito moderno e fora incluída nas Constituições do México (1917) e de Weimar, na Alemanha (1919). A partir de então, há, na propriedade, o surgimento de um Direito Constitucional, integrando o Direito público e fazendo-o servir a interesses coletivos.

No Brasil, ainda que de maneira acanhada, a Constituição de 1934 traçou um panorama de proteção a interesses difusos. Aliás, vale mencionar que o primeiro Código 
Florestal Brasileiro é datado deste período (1934), tendo sido publicado durante o governo de Getúlio Vargas. A Constituição de 1947 e, em evolução, as Constituições sucessoras (1967 e 1969), traçaram elementos de interesse coletivo jungidos à bens particulares, dando-lhes, portanto, uma função social a contemplar.

Neste período, a defesa do meio ambiente, inserida na lista dos interesses difusos, foi posta em protagonismo, pois, com a ascensão da "Era JK" tinha-se um acelerado processo de desenvolvimento no país. A legislação teve importantes marcos nesse período, como, exemplificadamente, a publicação do Estatuto da Terra - Lei 4.504/64 e o próprio Código Florestal - Lei 4.771/65, além da criação do Parque Ecológico das Cataratas do Iguaçú (1958).

No contexto mundial, a Conferência sobre o Meio Ambiente em Estocolmo (1972) é o principal símbolo de preservação ambiental e, também, do surgimento oficial do conceito de sustentabilidade, que, segundo definição da Comissão Mundial sobre o Meio Ambiente e Desenvolvimento (CMMAD) da Organização das Nações Unidas, o desenvolvimento sustentável é aquele que atende às necessidades presentes sem solocar em risco a possibilidade de que as gerações futuras satisfaçam as suas próprias necessidades.

Após, já na década de 80, após sucessivas crises ambientais, a Comissão Brundtland, pôs em circulação um relatório com a expressão desenvolvimento sustentável, fazendo com que o mundo contemplasse a necessidade de constituir um desenvolvimento econômico, um desenvolvimento social e proteção ambiental. Nas palavras de Magri (2017, p. 206), “a sustentabilidade seria um compromisso de equilíbrio entre o homem e o meio ambiente".

No Brasil todo o destaque ao tema "função social” e "função ambiental" consolidouse com o advento da Constituição Federal de 1988 (art. 186, art. 225), seguida da criação de importantes legislações (Lei dos Crimes Ambientais; Lei da Política Agrícola, Lei da Reforma Agrária, entre outras), atingindo o ápice social com a ECO 92 realizada no Rio de Janeiro.

Esta tendência é mundial e o Brasil caminha no mesmo trilho de países americanos e europeus, muito em razão da globalização. É de frisar o acontecimento da COP 21, realizado em Paris (2015) e os compromissos assumidos pelo Brasil para efetivação de medidas de mitigação dos percalços climáticos até o ano de 2030, destacando-se tarefas para regularização da economia de emissão de baixo carbono e erradiacação dos desmates ilegais.

Neste sentido é que o Código Florestal encaixa-se como legislação que visa sistematizar a sustentabilidade sócio econômica e ambiental. O Código Florestal Brasileiro, atualmente regulado pela Lei $\mathrm{n}^{\circ} 12.651$, de 25 de maio de 2012, estabelece limites de uso da 


\section{A SEPARAÇÃO ENTRE PODERES, AS DECISÕES JUDICIAIS E A LEI DO CÓDIGO FLORESTAL: INTERCESSÕES DE UM DEBATE NECESSÁRIO EM UMA SOCIEDADE DEMOCRÁTICA}

propriedade, que deve respeitar a vegetação existente na terra, considerada bem de interesse comum a todos os habitantes do Brasil. Mas, é preciso distinguir sua finalidade. Trata-se de lei nova (2012), que procurou adequar-se ao perfil contemporâneo dos conflitos e das demandas.

Porém, como nos relata a história do processo de criação desta lei, foi alvo de intenso embate entre setores considerados antagônicos. De um lado os produtores rurais e seus representantes clamavam por flexibilização das leis e, de outro lado, os ambientalistas, ONGs e outros membros representativos tinham receio de que o afrouxamento das leis impusesse ao meio ambiente e a toda a sociedade um desastre ecológico.

As principais alterações do "novo código" repousaram em tópicos envolvendo ARL'S (áreas de reserva legal), APP'S (áreas de preservação permanente), além de possibilidade de compensação de multa em áreas consolidadas (ocupação anterior a 2008) com reflorestamento e, em destaque, incentivo financeiro aos proprietários que façam a preservação das áreas verdes, segundo a lei.

Apesar de vigente, desde a publicação do novo Código Florestal Brasileiro, em 2012, há uma intensa discussão sobre a constitucionalidade de seus artigos. E esta discussão foi judicializada. Está em pauta de julgamento perante o STF - Supremo Tribunal Federal, desde 2013, as seguintes Ações Diretas de Inconstitucionalidade (ADIs): n 4901, nº 4902, nº 4903 e n 4937, as três primeiras movidas pela Procuradoria Geral da República (PGR) e a última pelo Partido Socialismo e Liberdade (PSOL). ${ }^{3}$

\footnotetext{
${ }^{3}$ ADI (4901) questiona, entre outros dispositivos, o artigo 12 (parágrafos $4^{\circ}, 5^{\circ}, 6^{\circ}, 7^{\circ}$ e $8^{\circ}$ ), que trata da redução da reserva legal (em virtude da existência de terras indígenas e unidades de conservação no território municipal) e da dispensa de constituição de reserva legal por empreendimentos de abastecimento público de água, tratamento de esgoto, exploração de energia elétrica e implantação ou ampliação de ferrovias e rodovias. Outros pontos questionados são os que preveem a compensação da reserva legal sem que haja identidade ecológica entre as áreas e a permissão do plantio de espécies exóticas para recomposição da reserva legal. O novo Código ainda permite a consolidação das áreas que foram desmatadas antes das modificações dos percentuais de reserva legal, item que também é questionado; ADI (4902) questiona temas relacionados à recuperação de áreas desmatadas, como a anistia de multas e outras medidas que desestimulariam a recomposição da vegetação original. O primeiro tópico questionado, o parágrafo $3^{\circ}$ do artigo $7^{\circ}$, permitiria novos desmatamentos sem a recuperação daqueles já realizados irregularmente. $\mathrm{O}$ artigo 17 , por sua vez, de acordo com a ADI, isentaria os agricultores da obrigação de suspender as atividades em áreas onde ocorreu desmatamento irregular antes de 22 de julho de 2008. Questiona, também, os artigos 59, 61 e 63. A ADI (4903) questiona a redução da área de reserva legal, clamando sejam declarados inconstitucionais os seguintes dispositivos da Lei ${ }^{\circ} 12.651 / 12$ : artigo $3^{\circ}$, incisos VIII, alínea b, IX, XVII, XIX e parágrafo único; artigo $4^{\circ}$, III, IV, parágrafos $1^{\circ}, 4^{\circ}, 5^{\circ}, 6^{\circ}$; artigos $5^{\circ}, 8^{\circ}$, parágrafo $2^{\circ}$; artigos 11 e 62 . A ADI (4937) pede a inconstitucionalidade do artigo 47 do Código Florestal, por violar a função socioambiental. Rechaça a criação da Cota de Reserva Ambiental (CRA), título normativo representativo de área com vegetação nativa, existente ou em processo de recuperação, prevista pela nova legislação. No entanto, esta transferência de tutela do bem ambiental para as leis da oferta e da procura e de acordo com o custo de oportunidade se materializa como um indutor do desmatamento, segundo o PSOL. Segundo o PSOL, a cota de reserva ambiental e a servidão ambiental não estão em conformidade com o artigo 225, caput, e parágrafo $1^{\circ}$, incisos I e III, da Constituição Federal.
} 
Desde os primeiros debates para anuência e outorga do texto, houve intenso debate entre os grupos envolvidos, sobretudo ruralistas e ambientalistas, o que culminuou, mesmo após a entrada em vigor da lei, na continuação do embate agora pela via da judicialização.

Resultado da crise do Poder Judiciário no Brasil, esta matéria (Código Florestal) gera insegurança jurídica, primordialmente em razão da demora para o julgamento da constitucionalidade ou não dos artigos em discussão pelo Supremo. Merece destaque a fala de Édis Milaré ${ }^{4}$ durante a audiência pública:

(I) a nova lei florestal não é perfeita, todavia, o caminho a seguir é perseguir os meios mais adequados para a efetiva implementação dos desígnios do legislador; (II) há um ponto que permeia todas essas discussões relativas ao Código, que é a busca pelo equilíbrio ecológico, que é garantido pelo artigo 225 da Constituição Federal; e (III) equilíbrio ecológico não é equivalente a ambiente intocável, logo, o que deve ser analisado é se a lei aprovada em 2012 é suficiente ou não para garantir o equilíbrio ecológico de acordo com o insculpido na Constituição Federal.

A insegurança jurídica, em vias práticas, nada mais é do que a corporizacão do desgaste do Poder Judiciário perante a sociedade, uma sociedade que, inclusive, enfrenta variados problemas econômicos que agravam o número de conflitos e tensões sociais. O Poder Judiciário enfrenta um elevado número de processos e um aumento das prestensões resistidas postas a crivo. No cômputo estatístico, essa crise se dá pois entram mais processos (problemas) do que saem (soluções).

O primeiro grau de jurisdição é o segmento mais sobrecarregado do Poder Judiciário e, por conseguinte, aquele que presta serviços judiciários mais aquém da qualidade desejada. Dados do Relatório Justiça em Números $2015^{5}$ revelam que dos 99,7 milhões de processos que tramitaram no Judiciário brasileiro no ano de 2014, 91,9 milhões encontravamse no primeiro grau, o que corresponde a $92 \%$ do total.

Os dados demonstrados pelo CNJ, na Revista Justiça em Números (2016, p. 19), bem como, os indices infrográficos do Jornal O GLOBO ${ }^{6}$ apontam um estoque de processos que totalizavam, até o ano de 2015, 73,9 milhões de ativos. Por outro lado, o índice de conciliação, aponta, em média, que apenas $9,4 \%$ das sentenças e decisões foram homologatórias de acordo.

4 Disponível em: http://www.milare.adv.br/pt/noticias/502-realizada-ontem-audiencia-publica-para-debater-ainconstitucionalidade-de-dispositivos-do-novo-codigo-florestal <acesso em 21/08/2017>

5 Disponível em http://www.cnj.jus.br/programas-e-acoes/politica-nacional-de-priorizacao-do-1-grau-de-jurisdicao/dadosestatisticos-priorizacao_<acesso em 21/08/2017>

${ }^{6}$ Disponível em: http://infograficos.oglobo.globo.com/brasil/conheca-os-numeros-3.html <acesso em 21/08/2017> 


\title{
A SEPARAÇÃO ENTRE PODERES, AS DECISÕES JUDICIAIS E A LEI DO CÓDIGO FLORESTAL: INTERCESSÕES DE UM DEBATE NECESSÁRIO EM UMA SOCIEDADE DEMOCRÁTICA
}

A despeito disso, sob a égide do Direito Ambiental, mais precisamente em relação à aplicação ou não do Código Florestal, existem duas problemáticas geradoras de insegurança jurídica: (a) a demora do STF no julgamento das ADIS sobre o Código Florestal, deixando-o em uma situação sub-judice, suscetível a variadas interpretações; (b) decorrente do primeiro cenário, o desvirtuamento da separação de poderes, onde na aplicação diante do caso concreto encontramos comandos diversos.

Ora, a não observância da Constituição Federal materializa a violação à premissa da separação dos poderes, que, em tese, devem ser independentes e harmônicos entre si. As competências estão distribuídas entre os poderes e demandam observância conforme limites impostos a cada ente. Segundo PARRA (2017, p. 161 e 162):

\begin{abstract}
Ao poder executivo foi reservada uma ampla gama de competências na efetivação da tutela ambiental, destacando-se o poder regulamentar administrativo e o poder de polícia. Paralelamente, ao poder Legislativo cabe atuação complementar (...) cujas leis e normas (federais, estaduais e municipais) balizam a atuação do Estado em material de tutela ambiental.
\end{abstract}

Desta forma, é competência do Poder Judiciário, a quem cabe o exercício do poder em nome do Estado, a aplicação da lei. Não cabe, portanto, aos membros do Poder Judiciário e, analogicamente, aos representantes do Ministério Público (órgão independente e essencial à justiça), o poder de legislar sobre a aplicabilidade ou não das leis. A opção para a não obrigatoriedade da aplicação do Código Florestal seria a revogação da lei pelo Congresso ou, de maneira judicial, em havendo violação expressa à Constituição, segundo decisão do STF.

\section{OS EFEITOS DA INSEGURANÇA JURÍDICA PARA A MANUTENÇÃO DA DEMOCRACIA, DA ORDEM SOCIAL E DA ESTABILIDADE DA ECONOMIA}

O Brasil, na década de 40, era composto por uma população eminentemente rural, de caráter familiar. Passados 40 anos, nos idos da década de 80, este cenário fora invertido e o país passou por uma troca de identidade geo-ocupacional, passando a ser ocupado em quase $70 \%$ por uma população urbana, segundo dados divulgados pela UNESP ${ }^{7}$.

Com o processo de urbanização houve, também, a inserção de novas tecnologias, industrialização, abertura de mercados externos e, passados quase quatro décadas, o

\footnotetext{
${ }^{7}$ Disponível em: http://www2.fct.unesp.br/nera/atlas/caracteristicas_socioeconomicas_b.htm <acesso em 21.08.2017>
} 
agronegócio (denominação da composição da cadeia produtiva rural) solidificou-se como principal figura da economia brasileira.

Dentre os componentes da cadeia produtiva do agronegócio, merece destaque a atividade agropecuária, que representou para o Brasil, no primeiro trimestre de 2017, $1 \%$ de elevação do PIB (Produto Interno Bruto). Segundo dados do $\mathrm{IBGE}^{8}$ foi a maior expansão em mais de 20 (vinte) anos, com salto de 13,4\% em relação ao trimestre imediatamente anterior.

Este resultado favorável é proveniente da safra recorde de grãos, colhida no primeiro trimestre de 2017 e que impulsionou a alta da economia brasileira como um todo, depois de um periodo de recessão de 2 (dois) anos.

O PIB permite classificar o desempenho de uma economia em termos de crescimento, desaquecimento, recesso ou depressão econômica e sob este conceito estão intimamente ligados os conceitos de renda per capita e bem estar social, parafraseando Bacha (2015, p 25).

O papel da agropecuária também é visível no meio social, haja vista que, segundo pesquisa divulgada pelo $\mathrm{IBGE}^{9}$, um em cada três brasileiros é empregado pelo agronegócio (sistema agroindustrial onde a agropecuária está inserta).

Buranello (2013, P. 33) nos define como se dá a caracterização da terminologia agronegócio e o papel da agropecuária no setor:

\begin{abstract}
Atualmente, o agribusiness, ou complexo agroindustrial, é composto por inúmeros sistemas ou cadeias agroindustriais (CAI), dos mais diversos produtos de origem vegetal ou animal. Os sistemas ou cadeias agroindustriais são todos os participantes envolvidos na produçãoo, processamento e marketing de produto específico. Analisando os segmentos existentes nas atividades agropecuárias e a função instrumental dodireito para disciplinar sua implementaçãoo, podemos dividir o sistema agroindustrial em três fases:

(...)

b) segmento dentro da porteira: constituído pela produçãoo propriamente dita, desde o preparo para a produçãoo até a obtenção do produto para comercialização. Neste segmento são aplicadas diversas normas de caráter contratual, de tutela ambiental e trabalhista, bem como os contratos agrários e seu regime especial. As normas jurídicas ambientais dizem respeito ao cuidado que se deve tomar quanto ao uso de agrotóxicos, às formas de exploraçãoo da terra e, principalmente, dispõe acerca da utilização dos recursos hídricos. As contingências trabalhistas estão bem definidas nas normas de segurança e proteçãoo ao trabalhador rural.
\end{abstract}

\footnotetext{
8 Disponível em: http://g1.globo.com/economia/noticia/pib-do-brasil-cresce-10-no-1-trimestre-de-2017.ghtml <acesso em 21.08.2017>

${ }^{9}$ Disponível em : https://www.agrolink.com.br/noticias/agronegocio-emprega-1-3-dos-brasileiros_394016.html <acesso em 21.08.2017>
}

Rev. de Direito Agrário e Agroambiental | e-ISSN: 2526-0081| Maranhão | v. 3 | n. 2 | p. 99 - 115 | Jul/Dez. 2017 


\section{A SEPARAÇÃO ENTRE PODERES, AS DECISÕES JUDICIAIS E A LEI DO CÓDIGO FLORESTAL: INTERCESSÕES DE UM DEBATE NECESSÁRIO EM UMA SOCIEDADE DEMOCRÁTICA}

A exploração da terra de maneira econômica é albergada pelo direito brasileiro, mas, como vimos, trata-se de um direito de propriedade/posse relativo, pois, para que seja tutelado, precisa cumprir com os regramentos da função social da terra (art. $186 \mathrm{CF}$ ), com ênfase (ainda que não decorrente da lei) à preservação ambiental e a persecução da sustentabilidade (ponto de equilírio), à medida em que a Constituição Federal tutela o direito de propriedade em seu art, 5, XXII e XXIII. OPTIZ (2016. P. 82 e 83) enaltece o caráter empresarial da moderna atividade rurícola no Brasil, com base no Estatuto da Terra:

O art. 4, VI, dispõe: "Empresa rural é o empreendimento de pessoa física ou jurídica, pública ou privada, que explore econômica e racionalmente imóvel rural, dentro do rendimento econômico da região em que se situe e que explore a área mínima agricultável do imóvel, segundo padrões fixados, pública e previamente pelo Poder Executivo".

Mais adiante, como veremos, o conceito econômico e social conferido ao uso da terra também é contemplado na Constituição Federal, no artigo 170. Tratando da atividade agropecuária, ou seja, da exploração da terra em atividades rurícolas, este é o quadro de ocupação do território brasileiro (2016), segundo dados do IBGE, em parceria com o GITE EMBRAPA $^{10}$ :

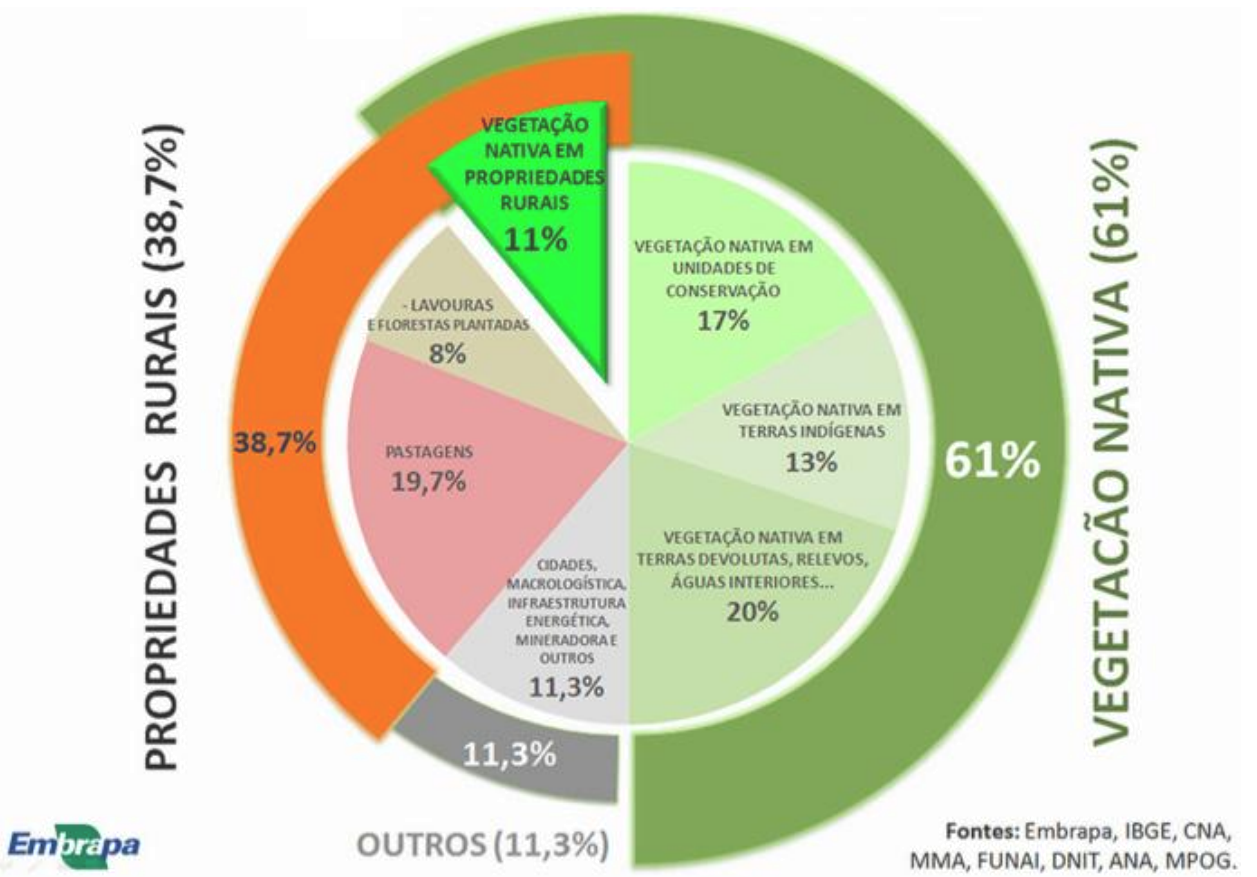

10 Extraído de: http://observatorioabc.com.br/2017/02/no-brasil-salvacao-da-biodiversidade-do-meio-ambiente-e-daeconomia-esta-na-agropecuaria-diz-pesquisador-da-embrapa/ <acesso em 21/08/2017>

Rev. de Direito Agrário e Agroambiental | e-ISSN: 2526-0081| Maranhão | v. 3 | n. 2 | p. 99 - 115 | Jul/Dez. 2017 
Os dados do IBGE para o mês de maio de 2017, segundo reportagem da Revista DBO (junho, 2017. P. 9) demonstram um aumento na área de vegetação nativa em propriedades rurais, saltando, em um ano, de $11 \%$ para $20,5 \%$, sendo que a vegetação nativa passou de $61 \%$ para 66,3\%. O Cadastro Ambiental Rural, criado pelo Código Florestal, pode ser considerado instrumento na busca pela preservação ambiental e é ponto de consenso entre os vários grupos (produtores rurais, ambientalistas, advogados, órgãos públicos). Vejamos os números de aderência ao programa, pelas propriedades rurais do Brasil, segundo dados da EMBRAPA ${ }^{11}$ :
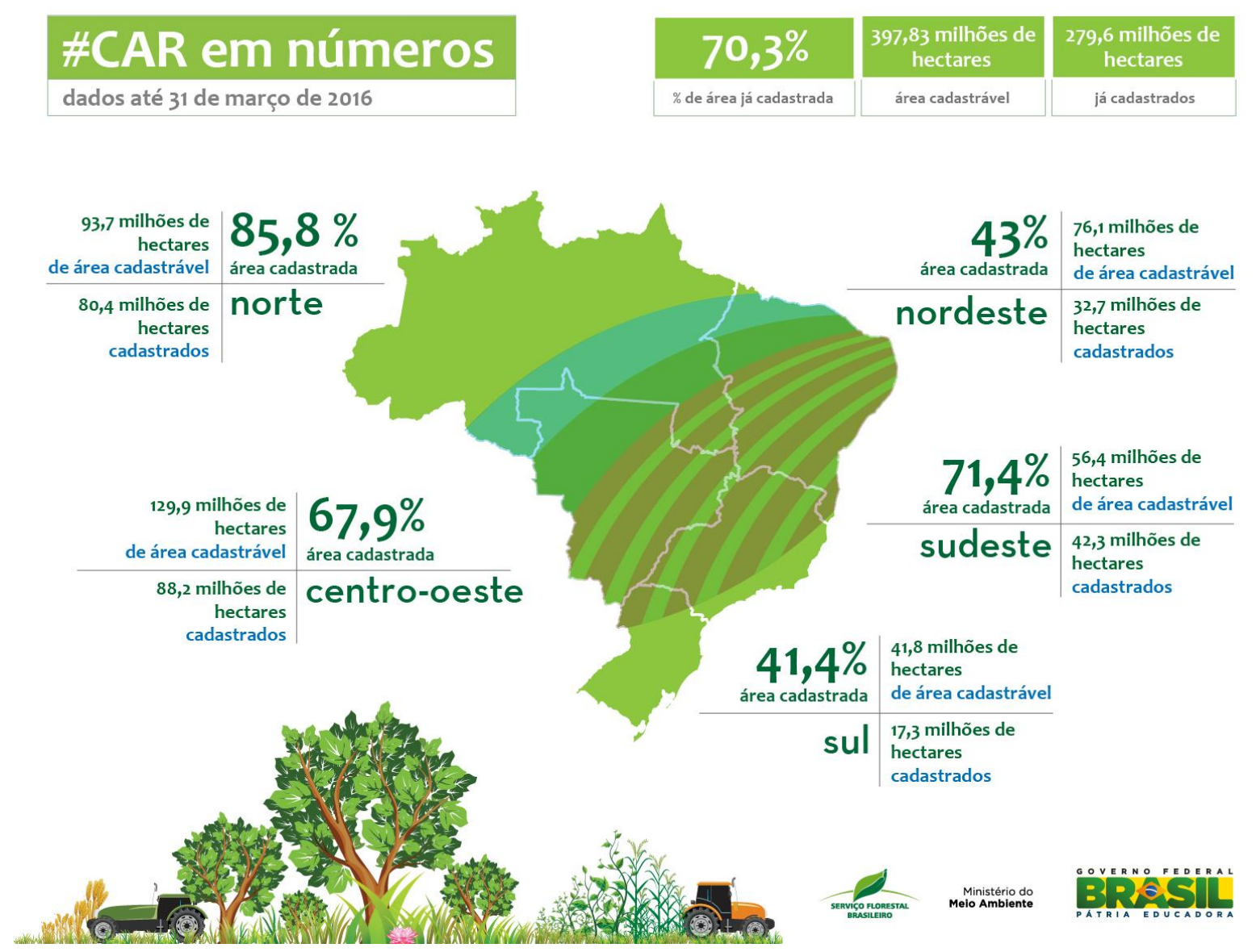

Estima-se que no Brasil, atualmente, existam mais de 5 milhões de propriedades rurais cadastradas no INCRA ${ }^{12}$. Desde pequenas e médias áreas até os grandes latifúndios, que utilizam aproximadamente $28 \%$ do territorio brasileiro efetivamente em exploração. O que ambas, grandes e pequenas propriedades têm em comum é o dever de observância às leis

\footnotetext{
${ }^{11}$ Disponível em: https://www.cnpm.embrapa.br/projetos/car/materialmetodos.html <acesso em 21/08/2017>

12 Disponível em:

http://www.incra.gov.br/media/politica_fundiaria/regularizacao_fundiaria/estatisitcas_cadastrais/imoveis_total_brasil.pdf <acesso em 10/03/2017>
}

Rev. de Direito Agrário e Agroambiental | e-ISSN: 2526-0081| Maranhão | v. 3 | n. 2 | p. 99 - 115 | Jul/Dez. 2017 


\section{A SEPARAÇÃO ENTRE PODERES, AS DECISÕES JUDICIAIS E A LEI DO CÓDIGO FLORESTAL: INTERCESSÕES DE UM DEBATE NECESSÁRIO EM UMA SOCIEDADE DEMOCRÁTICA}

ambientais. Esse dever decorre da imposição do art. 225 (que visa garantir um meio ambiente ecologicamente equilibrado), aplicado, conjuntamente com o comando do art. 186, que reveste a propriedade rural de uma função social, como já previsto no art. $5^{\circ}$, XXII e XXIII, todos da Constituição Federal:

\footnotetext{
Art. $5^{\circ}$ Todos são iguais perante a lei, sem distinção de qualquer natureza, garantindo-se aos brasileiros e aos estrangeiros residentes no País a inviolabilidade do direito à vida, à liberdade, à igualdade, à segurança e à propriedade, nos termos seguintes:

$(\ldots)$

XXII - é garantido o direito de propriedade;

XXIII - a propriedade atenderá a sua função social;

Art. 186. A função social é cumprida quando a propriedade rural atende, simultaneamente, segundo critérios e graus de exigência estabelecidos em lei, aos seguintes requisitos:

I - aproveitamento racional e adequado;

II - utilização adequada dos recursos naturais disponíveis e preservação do meio ambiente;

III - observância das disposições que regulam as relações de trabalho;

IV - exploração que favoreça o bem-estar dos proprietários e dos trabalhadores.
}

Outrossim, é possível concluir que a matéria ambiental, enquanto direito fundamental, abraça os conceitos de democracia, ordem social - e seus sub-ramos de bem estar e justiça - e crescimento econômico. A própria Constituição Federal tratou de jungir todos os conceitos, abarcando a ideia de bases constitucionais da economia (arts. 170 a 192):

\footnotetext{
Art. 170. A ordem econômica, fundada na valorização do trabalho humano e na livre iniciativa, tem por fim assegurar a todos existência digna, conforme os ditames da justiça social, observados os seguintes princípios:

(...)

III - função social da propriedade;

(...)

VI - defesa do meio ambiente, (...).
}

O viés ambiental da função social (art. II do art. 186), portanto, está entrelaçado à envergadura econômica (inciso I do art. 186) e, também, ao liame social (incisos II e IV do art. 186). A principal lei balizadora dos deveres inerentes a todos os segmentos é o Código Florestal. Note-se, portanto, que a situação que permeia o referido marco legal norteador da atividade rurícola na definição dos comandos legais gera insegurança jurídica e impacta significativamente a sociedade em suas diversas dimensões afetadas.

A insegurança jurídica adstrita às relações ambientais que dependem do Código Florestal poderá gerar impactos em todos os setores envolvidos. Em linhas gerais, poderá 
onerar o setor produtivo e lhe incumbir uma redução de rendimentos que, invariavelmente, será repassada à sociedade, através da estagnação da economia, da recessão de empregos, e do aumento de preços no mercado financeiro. O judiciário exerce, portanto, um meio de controle político e econômico nos mais variados setores. Assim, sua inércia frente à decisão das ADIS que versam sobre o Código Florestal impacta desfavoravelmente nos quesitos econômicos, de ordem social e de democracia.

NUSDEO (2016, p. 39) faz a congruência entre direito e economia, nessas palavras:

Economia e Direito são assim indissociáveis, pois as relações básicas estabelecidas pela sociedade para o emprego dos recursos escassos são de caráter institucional, vale dizer, jurídico. Por outro lado, as necessidade econômicas influenciam a organização institucional e a feitura das leis. De qualquer maneira, não existe fenômeno econômico não inserido em um nicho institucional.

Por tudo isso, conclui-se que a matéria ambiental, no que tange ao Código Florestal, guarda estreita ligação com outros ramos (do Direito e da Administração) e, dada essa natureza interdisciplinar, culmina em consequências que impactam a economia e a ordem estatal, via de regra, muito em razão dos dados aqui já referenciados, de importância do agronegócio na economia (elevação do PIB) e na ordem social (geração de empregos), muito em razão da tensão social e econômica aflorada, onde produtores rurais não sabem qual ordenamento cumprir, os ambientalistas não tem a certeza de qual norma está em vigor e os tribunais interpretando de formas distindas as mesmas questões, deixando de criar, assim, jurisprudência sobre o assunto.

\section{CONSIDERAÇÕES FINAIS}

A problemática enfrentada foi saber qual a importância do Poder Judiciário para manutenção da democracia, da ordem social e estabilidade econômica e jurídica a partir de problematização ambiental.

Assim, a Política e a Economia invadiram o Direito, fazendo-o assumir um caráter multidisciplinar perante e, principalmente, os Direitos Fundamentais. Prosseguindo, diz-se que a economia está ligada à natureza, é uma união visceral entre o homem, o meio ambiente e a produção econômica.

Rev. de Direito Agrário e Agroambiental | e-ISSN: 2526-0081| Maranhão | v. 3 | n. 2 | p. 99 - 115 | Jul/Dez. 2017 


\section{A SEPARAÇÃO ENTRE PODERES, AS DECISÕES JUDICIAIS E A LEI DO CÓDIGO FLORESTAL: INTERCESSÕES DE UM DEBATE NECESSÁRIO EM UMA SOCIEDADE DEMOCRÁTICA}

Esta conjunção é facilmente verificada pela leitura do art. 225 da Constituição Federal e do art. 170, VI da Constituição Federal, conforme citamos anteriormente. E o Estado tem um papel fundamental e preponderante no atendimento à legislação.

Vejam que a CF 88 tratou de costurar a relação entre sociedade e poder público, traçando deveres conjuntos. Na concepção de Estado, estão inseridos todos os brasileiros.

E é por isso que o Estado tem papel de destaque para contornar interesses conflitantes e agir em verdadeira precaução, para respeito aos direitos individuais e coletivos.

O Estado não tem apenas um papel econômico na sociedade, é uma estrutura básica social. E não se pode esquecer que a máquina estatal depende de recursos para sobreviver, recursos estes que advém da sociedade, através de impostos, taxas, etc. Por isso, como relatado no começo, economia e meio ambiente estão intimamente ligados, também, a questões sociais.

E como toda a arrecadação e o caixa estatal provém da sociedade, uma baixa produção e pouca circulação de verba na economia empresarial e industrial impacta negativamente, de modo imediato, nas atividades do Estado. Por isso a preocupação com a insegurança jurídica posta ao setor do agronegócio.

É inegável que a sociedade tem direito ao meio ambiente ecologicamente equilibrado e, que é dever do Estado tutelar este direito para garanti-lo as presentes e futuras gerações. Todavia, não obstante, o cidadão tem a prerrogativa de, segundo o art. $5^{\circ}$, II, CF/88, somente ser obrigado a fazer ou deixar de fazer alguma coisa em virtude de lei. A não aplicação da lei, em matéria ambiental, em casos onde é exigida afronta o Estado democrático de Direito e gera insegurança jurídica..

Em outras palavras, há que se estabelecer o desenvolvimento sustestável, encontrando o ponto de equilíbrio entre preservação do meio ambiente e crescimento econômico. Somente dessa forma a democracia sera alcançada e os interesses coletivos e individuais chancelados. E é justamente esta questão que deve ser analisada pelo STF, se a lei florestal é garantidora ou não dos direitos ambientais prelecionados pela Constituicão Federal. Por consequência, a insegurança jurídica é fruto da demora do STF em exarar seu veredicto, notadamente sobre um assunto de tamanha relevância para o país.

Rev. de Direito Agrário e Agroambiental | e-ISSN: 2526-0081| Maranhão | v. 3 | n. 2 | p. 99 - 115 | Jul/Dez. 2017 


\section{REFERÊNCIAS}

PARRA, Rafaela Aiex. Função Social da Propriedade Rural | Noções Gerais do Aspecto Ambiental e o Direito de Propriedade. Jundiaí: Grappe Editorial, 2017.

REVISTA JUSTIÇA EM NÚMEROS, ANO 2016. FONTE: CNJ. Disponível em: http://www.cnj.jus.br/files/conteudo/arquivo/2016/10/b8f46be3dbbff344931a933579915488. pdf

REVISTA DBO. JUNHO 2017.

BACHA, Carlos José Caetano. Entendendo a Economia Brasileira. 3. ed. São Paulo: Alínea, 2015.

BURANELLO, Renato. Manual do Direito do Agronegócio. São Paulo: Saraiva, 2013.

CONSTANT, Benjamin. Da liberdade dos antigos comparada à dos modernos. In.: MONTEIRO, João Paulo e ou. Filosofia Política 2. Porto Alegre: L\&Pm Editores (UNICAMP/UFRGS - com apoio do CNPQ), 1985.

FACHIN, Zulmar. Teoria Geral do Direito Constitucional. 2. ed. Londrina: IDCC Instituto de Direito Constitucional e Cidadania, 2006.

MAGRI, Ronald Victor Romero; MAGRI, Cinthia Hialys Koziura. Algumas reflexões sobre sustentabilidade. Direito do Agronegócio. Revista do Advogado, São Paulo: Rettec, n. 134, p. 204-210, jul. 2017

MELLO, Celso Antônio Bandeira de. Discricionariedade e Controle Jurisdicional. 2. ed. São Paulo: Malheiros, 2017.

MILARÉ, Édis; MORAIS, Roberta Jardim de; DIAs, Maria Camila Cozzi Pires de Oliveira. Reencontrando Derrida. Direito Ambiental. Revista do Advogado, São Paulo: Rettec, n. 133, p. 23-38, mar. 2017.

NUSDEO, Fábio. Curso de Economia: Introdução ao Direito Econômico. 10.ed. São Paulo: Revista do Tribunais, 2016.

OPITZ, Silvia Carlinda Barbosa; OPITZ, Oswaldo. Curso completo de Direito Agrário. 10. ed. São Paulo: Saraiva, 2016.

RIZZARDO, Arnaldo. Curso de Direito Agrário. São Paulo: Revista dos Tribunais, 2013.

SILVA, José Afonso da. Curso de Direito Constitucional Positivo. 23. ed. São Paulo: Malheiros, 2004. 
SOARES, Marcos Antônio Striquer; ARAUJO JR, Miguel Etinger de; AMARAL, Ana Claudia Corrêa Zuin Matos de. Estudos em Direito Negocial e Democracia. São Paulo: Boreal, 2016. 